\title{
DIGITAL DIVIDE'S THREE TIERS INTERACTION: A CONCEPTUAL MODEL FROM THE PERSPECTIVE OF TASK-TECHNOLOGY FIT
}

\author{
Edgardo R. Bravo, Universidad del Pacifico,er.bravooo@up.edu.pe \\ Christian Fernando Libaque-Saenz, Universidad del Pacifico, cf.libaques@up.edu.pe
}

\author{
Research in Progress
}

\begin{abstract}
Information and Communication Technologies (ICTS) have led the world to a new economy supported by the interactions of individuals through the Internet and the use of this technology. The term digital divide, on the other hand, represents the gap between those who use the Internet and those who cannot. It is a multidimensional concept consisting of three stages: access, use, and outcomes. The first stage refers to the physical infrastructure, the second to the intensity of use of this technology, while the third refers to the benefits associated with the use of this technology. The third stage is important because benefits could embrace economic growth and social inclusion, for example. However, prior research has focused mainly on the two first stages. Our research aims to propose a framework to analyze the three digital divide stages through the task-technology fit lens, which is a model that includes user perception of the fit between task requirements and the Internet. We have also included an additional variable to account for the level of match between user skills and the Internet (user-technology fit). At the theoretical level, our results may provide a conceptual framework to assess the digital divide dimensions and their associated outcomes. In practical terms, strategies that match potential outcomes may be suggested.
\end{abstract}

Keywords: Digital divide, task-technology fit, user-technology fit, Internet outcomes

\section{INTRODUCTION}

Information and Communication Technologies (ICTs) have become important drivers of economic growth. Prior research has found a significant positive relationship between Internet penetration and economic power (Fink \& Kenny, 2003; UNDP, 2001). Indeed, ICTs have disrupted the way we work and live and thus a 'new economy' has emerged due to the development of these technologies (OECD, n.d.). However, these same technologies may act as a source of exclusion for those who are disconnected because they will not be able to participate in this new economy (Libaque-Saenz, 2016). This gap between those who have access and those who have not is known as the 'digital divide.' While the digital divide is not an issue related solely to rural and remote areas, it is usually associated with the distance to core network facilities. At the same time, the digital divide is usually associated with lack of skills (OECD, 2018). Hence, the digital divide does not refer only to the access to ICTs, but also to the levels of use of these technologies, especially the Internet.

Based on the above discussion, 'digital competence' has become a key concept in the discussion of the skills citizens must have in this Knowledge Society (van Laar et al., 2017). In recent years, studies have paid attention not only to Internet usage but also to its associated outcomes. These outcomes can be classified depending on whether they are beneficial or prejudicial, and if they stay online or can be transferred to the offline world. For example, van Deursen, Helsper and Eynon (2016) argued the need for clear separation between different kinds of activities in the digital sphere (i.e., digital resource fields) and their associated tangible outcomes in different spheres of everyday life (i.e., offline resource fields). However, van Deursen and Helsper (2015) pointed out that there is little empirical evidence on how Internet use and skills turn into specific outcomes, stating that there is a need to develop more detailed classifications of Internet-dependent outcomes.

Empirical evidence of the impact of Internet use on outcomes can be classified into specific and broad results. Research, however, has focused on specific results associated to the use of the Internet as follows: to establish social networks (Boase et al., 2006), to foster political participation (Sylvester \& McGlynn, 2010), to promote information 


\section{Issues in Information Systems}

Volume 20, Issue 4, pp. 188-197, 2019

about job opportunities (Kuhn \& Mansour, 2014), to increase income (DiMaggio \& Bonikowski, 2008), to obtain services and goods at better prices (Bhatnagar \& Ghose, 2004), among others. Accordingly, our study aims to propose and assess a model that includes the digital divide multidimensional concept, Internet use, and various related outcomes.

At the theoretical level, this research would provide a conceptual framework that improves the understanding of the stages of the digital divide and their associated outcomes. We will address the third stage of the digital divide to develop strategies that match potential outcomes. The paper proceeds as follows: Section 2 provides an explanation of the theoretical framework used in this research. Section 3 proposes the hypotheses and presents the research model. Finally, sections 4 and 5 discuss the research methodology and expected implications respectively.

\section{THEORETICAL FRAMEWORK}

\section{The Digital Divide}

The term 'digital divide' is defined by the OECD as the "gap between individuals, households, businesses and geographic areas at different socio-economic levels with regard both to their opportunities to access ICT and to their use of the Internet for a wide variety of activities" (OECD, 2001). Van Deursen and Helsper (2015) proposed that the digital divide is a multidimensional concept consisting of three stages. The first stage refers to the differences in access to ICT infrastructure, the second to user skills and online activity patterns, and the third relates to user ability to translate ICT usage into beneficial offline outcomes (van Deursen \& Helsper, 2015).

Chang, Wong, and Park (2016) proposed a 3-tier ICT access model, where the first tier (or objective-based beliefs) relates to users' experience and perceived system quality. This tier is also known as external access because it is not under user control and must be provided by external forces (e.g., social and technological access). The second tier (or behavioral beliefs) refers to affective and cognitive beliefs (Chang, Wong, \& Park, 2016). This tier is also known as internal access because users have the control. It depends on users' beliefs and behaviors, and presents two types of access: motivational and skills access (Chang, Wong, \& Park, 2016). Finally, the third tier represents user behavioral intention to participate in online activities (Chang, Wong, \& Park, 2016).

The van Deursen and Helsper (2015) study is a step forward in the research about the third stage of the digital divide. The authors formulated an operational framework to assess tangible outcomes of Internet use and relate these outcomes to the inequalities recognized by digital divide research. The framework used encompassed four concepts: 1) socio-demographic variables, 2) offline resources, 3) digital inclusion indicators, and 4) offline outcomes. This framework postulates that demographic variables impact on users' offline resources which in turn lead users to improve their digital inclusion indicators (i.e., access, skills, use and motivation). Finally, these indicators are associated with offline outcomes of online activities, which in turn may feed back into users' offline resources (van Deursen \& Helsper, 2015).

\section{Task-Technology Fit}

Goodhue and Thompson (1995) studied the impact of the fit between technology and the associated task on individual performance. The authors developed the Task-Technology Fit (TTF) model (see Figure 1) in which technology must have a good fit with the task in order to have a positive impact on individual performance. This TTF construct is defined as the level of correspondence between the technology functionality and the task requirements (Goodhue \& Thompson, 1995). The TTF model postulates that in cases where technology provides features and support that fit task requirements, this fit improves performance and usually the use of the technology. This framework has been widely used to assess how ICTs lead to performance and usage impacts (Lu \& Yang, 2014), allowing our research to focus on the third level of the digital divide (i.e., ICT outcomes). 


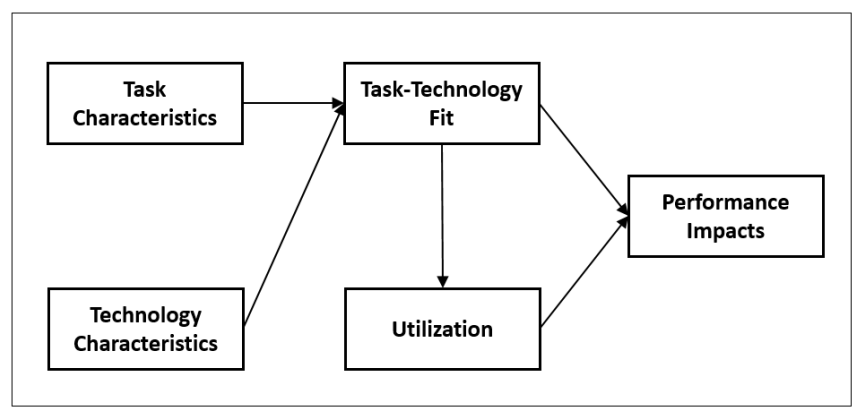

Figure 1. The Task-Technology Fit Model

Marcolin et al. (2000) assessed the TTF model and claimed that although this framework proposes that individual performance depends on a fit between the task, the technology, and individuals' characteristics, the last concept (individuals' characteristics) has not yet been addressed in detail. In fact, TTF was built on the Technology-ToPerformance Chain which postulates that technology utilization depends on both task and individual characteristics, the effects of which are moderated by technology characteristics (Goodhue \& Thompson, 1995). TTF focuses on perceptions of the task and technology but it does not contemplate the possibility that the outcomes can be limited by individuals' abilities, and not specifically by how the task is defined or how the technology is built (Marcolin et al., 2000). Hence, the inclusion of a variable that captures individual user characteristics and their interaction with technology is required. It is important to notice that a good fit between users and technology does not necessarily imply a good TTF value because we do not know the nature of the task.

In addition, Goodhue and Thompson (1995) warns that models focusing on fit alone, referring to the TTF model, do not pay enough attention to the fact that systems must be employed before they can reach performance impacts. Accordingly, Goodhue and Thompson (1995) suggest that the TTF model may benefit from the inclusion of important antecedents to utilization. In this context, since performance impacts are a consequence of continued use of a technology, we included two antecedents to utilization from the Continued Technology Use literature: satisfaction and attitude (Oghuma et al., 2015; Ha et al., 2015). The former is defined as a positive affective state resulting from users' assessment of the capabilities of the technology to meet their needs (Bhattacherjee, 2001), while the latter is defined as the general assessment of the psychological state that captures attributes such as goodbad (Ajzen, 2005). Satisfaction differs from attitude in the sense that the former is an affective evaluation of the behavior after performing it. Hence, satisfaction is particular to a context and transient in time. On the other hand, attitude is a more enduring assessment of the behavior over time (Bolton \& Drew, 1991; Liao, Palvia, \& Chen, 2009).

\section{RESEARCH MODEL}

Figure 2 shows our proposed research model. It addresses the three stages of the digital divide. The first stage includes user environmental constraints (i.e., access to infrastructure), the second covers skills, motivations, and technology use, and the third gives the results obtained. 


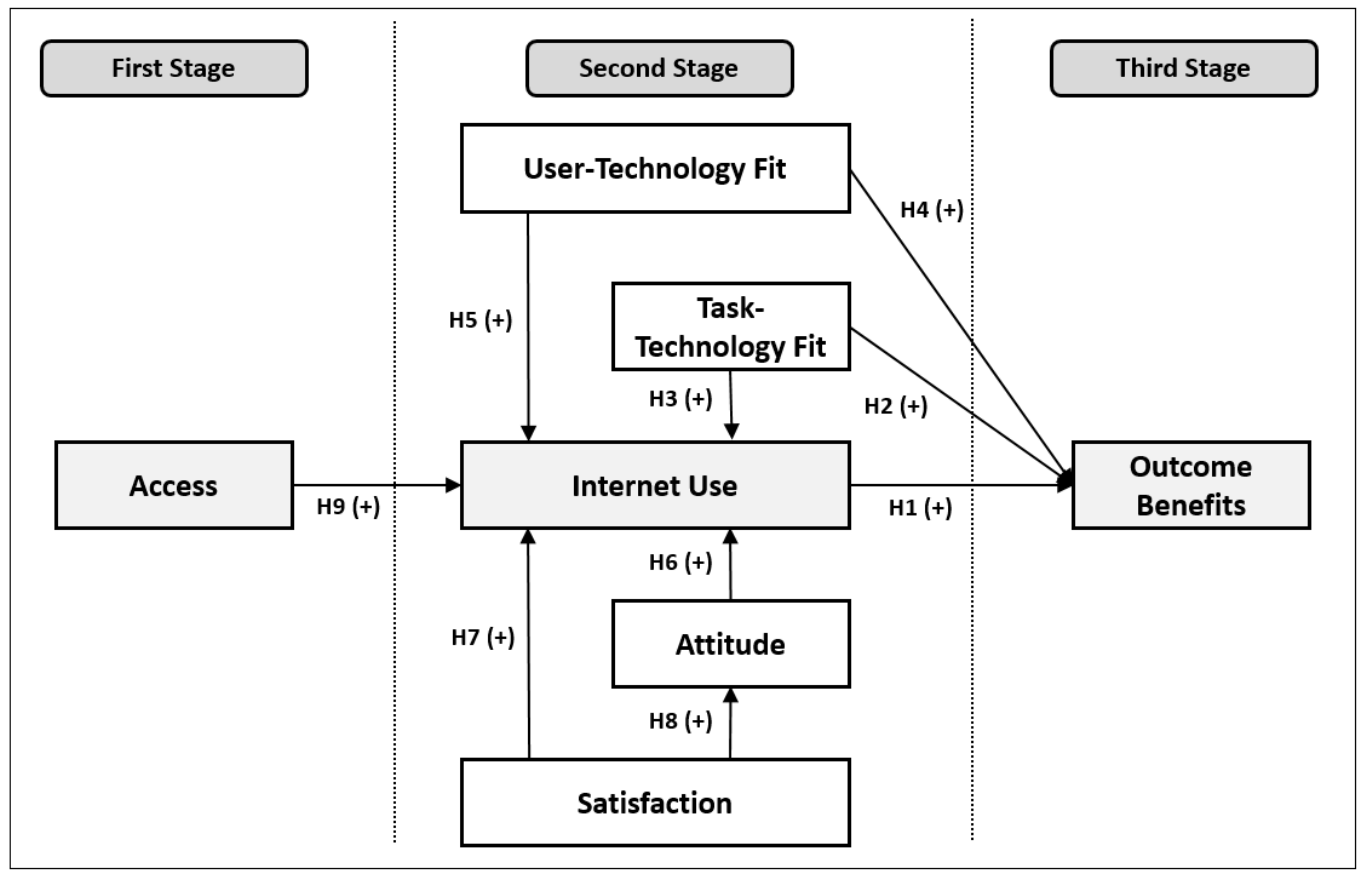

Figure 2. Research Model

In our research, the technology under study is the Internet. By following van Deursen and Helsper (2015)'s research on the outcomes of Internet use, we conceptualized outcome benefits in terms of economic, social, political, institutional, and educational metrics. In general, these benefits are defined as the extent to which the Internet contributes to the success of individuals (Petter, DeLone \& McLean, 2008). For example, the Internet has led to improved commerce due to its global nature that significantly reduces geographical barriers. Also, the Internet and the associated social network sites (SNSs) have disrupted the way we socialize. SNSs allow users to keep in touch with acquaintances in spite of geographical distance. These same networks allow citizens to easily share their political thoughts, while the Internet also provides institutional benefits such as those related to the interaction between government institutions and citizens. Finally, the Internet enables e-learning platforms that can boost education. Accordingly, previous studies have found a positive effect of Internet use on a broad concept of outcome benefits (DiMaggio \& Hargittai, 2001; Hargittai \& Hinnant, 2008; Helsper, 2012; van Deursen \& van Dijk, 2011). We hypothesize:

\section{H1: Internet use positively influences outcome benefits}

In the case of the TTF variable, we defined it as the level of match between Internet (i.e., technology) capabilities and the demands of the task that must be performed (Furneaux, 2012). Task is broadly defined as the actions carried out by individuals to turn inputs into outputs (Goodhue \& Thompson, 1995). Goodhue and Thompson (1995) propose that the use of a technology has a positive impact on its output only when there is a correspondence between the functionality of the technology and the task requirements. In other words, the better the match between the functionality of the technology and the task requirement, the more positive the outcome. For example, D'Ambra and Wilson (2004) found that a good fit is achieved when the Internet serves as the information source for a travel task, which benefits user searching by reducing uncertainty. Hence, we posit:

\section{H2: Task-technology fit positively influences outcome benefits}

As discussed in the above paragraph, TTF may influence the benefits associated with the utilization of a technology. In our research, utilization refers to the continuous use of the Internet to accomplish specific tasks. Accordingly, users who perceive that Internet capabilities match task requirements may be motivated to use this technology more than those who perceive a mismatch between Internet capabilities and the same tasks. For example, Lin and Huang 
(2008)'s research found that TTF has a positive effect on the use of knowledge management systems. We hypothesize:

\section{H3: Task-technology fit positively influences Internet use}

As discussed in the previous section, it is important to include a variable that captures the interaction between users and the technology. For example, Somers and Nelson (2001) found that lack of user skills to operate a software could lead to failure in its implementation. Previous literature has proposed the User-Technology Fit (UTF) variable for capturing this interaction, which can be considered as user procedural knowledge of the technology. UTF is linked to user understanding of software semantics and syntax (i.e., technology), and how to use these skills to fulfill a task (Sousa \& Goodhue, 2003; Sein, Bostrom \& Olfman, 1999). In our research, UTF is defined as the level of alignment between user skills and Internet functionalities. The more users know how the Internet works, the more they will be able to take advantage of this technology. For example, users who are skilled in the use of the Internet could engage in e-commerce activities and translate the use of this technology into monetary benefits. Accordingly, we posit:

\section{H4: User-technology fit positively influences outcome benefits}

If a user does not know how to handle a system, it is not possible to fully employ its functionalities. Hence, its usage may be limited. Fishbein (2000), for example, claimed that any behavior is likely to happen if the individual has the skills to perform it. Likewise, Marcolin et al. (2000) modified the TTF framework by introducing user competence and the associated causal relationship between this variable and technology use. For example, skilled users may perform a huge variety of activities through the Internet. Hence, it is probable that they spend more time on the Internet than inexperienced users, who can only perform a limited number of activities. Hence, we suggest:

\section{H5: User-technology fit positively influences Internet use}

As explained in the above section, the TTF model may benefit from the inclusion of important antecedents to utilization: attitude and satisfaction. In the case of attitude, our study conceives it as users' general assessment of the trade-off between the benefits and costs associated with Internet use (Ajzen, 2005). According to the Theory of Planned Behavior (TPB) (Azjen \& Fishbein, 2005), it is expected that intentions to carry out a given behavior will be greater for users with a favorable attitude toward the behavior than for those who have a negative attitude toward it (Fishbein \& Azjen, 2011). In addition, TPB posits that the best predictor of a behavior is behavioral intention, and thus attitude may impact user decision to perform a behavior or not (Montaño \& Kasprzyk, 2015). We hypothesize:

\section{H6: Positive attitude toward the Internet use positively influences Internet use}

As for satisfaction, we define it as users' negative (unsatisfied), indifferent, or positive (satisfied) feeling after using the Internet. The Theory of Technological Continuity (TTC) states that satisfaction primarily determines user intention to continue using a technology (i.e., the utilization of the technology). In other words, a post-usage evaluation of the technology is performed by users. If this evaluation is positive, users will feel satisfied and thus they will be motivated to continue using the technology (Bhattarcherjee, 2001). In contrast, if the assessment is negative, users will feel unsatisfied and motivated to avoid the use of it. We propose:

\section{H7: Satisfaction positively influences Internet use}

In addition, satisfaction and attitude both represent affective assessments of the use of a technology (Bhattacherjee \& Premkumar, 2004). Conceptually, satisfaction is a temporal and specific affection that occurs after technology use. Therefore, this temporal variable is expected to form a more persistent evaluation of the technology (i.e., attitude) (Bolton \& Drew, 1991; Oliver, 1981). Not surprisingly, Liao, Palvia and Chen (2009) postulates that both satisfaction and attitude are important constructs, but in distinct phases of the technology use cycle. For instance, Bhattacherjee and Premkumar (2004) proposed a framework that aims to clarify the change of attitudes in time. The authors found that satisfaction is an important antecedent to attitude generation. Hence, it is expected: 


\section{H8: Satisfaction positively influences attitude toward Internet use}

Access is a broad term and its definition depends on the context. In our study, we refer to access within the ICT context, particularly, the use of the Internet. Chang, Wong and Park (2016) state that technological access is the most fundamental access type. It refers to the availability and accessibility of tangible technologies such as personal computers, software, and Internet connections (Chang, Wong, \& Park, 2016). This concept can be seen as an external access which is provided by external forces such as governments, societies, and organizations (Chang et al., 2012; van Dijk, 2006). Technological access is important because it supports digital content. The more available the ICT infrastructure, the more accessible users will perceive the contents to be, which in turn may motivate the use of these technologies (Chang, Wong, \& Park, 2016). For example, van Dijk (2006) found that better infrastructure (high-speed broadband connections compared to old 56k dial-up modems) increases users' desire to use the Internet. In contrast, if access to the Internet has some restrictions, users may be motivated to avoid the use of this technology. Based on the previous discussion, we hypothesize:

\section{H9: Access positively influences Internet use}

\section{RESEARCH METHODOLOGY}

This is a research in progress, so this section describes future procedures.

\section{Measurement Instrument}

All variables will be measured as reflexive constructs. Attitude and satisfaction will be measured with 4 items each one from Liao, Palvia and Chen (2009). Other variables will be adopted from prior research as follows: access with 4 items (Chang, Wong, \& Park, 2016), Internet use with 3 items (van Deursen, van Dijk, \& ten Klootser, 2015), task-technology fit with 5 items (Goodhue \& Thomspon, 1995), user-technology fit with 5 items (van Deursen, van Dijk, \& Peters, 2012; van Deursen, Helsper \& Eynon, 2016; Edwards et al., 2006; Sousa, 2004), and outcome benefits with 8 items (van Deursen \& Helsper, 2015).

\section{Data Collection (Future Step)}

A survey will be used to collect users' responses to the items mentioned in the above paragraph. The sample will be formed by USA Internet users, and responses will be collected through Amazon Mechanical Turk. Previous studies have reported that samples collected through this website produced similar results to those based on USA consumer panels (Steelman, Hammer \& Limayem, 2014). Nevertheless, to detect careless responses we will include attentioncheck items and a warning statement that informs participants that statistical control methods will be used (Huang et al., 2012).

A pilot test will be conducted to assess the reliability and validity of our measurement items. For the full-scale sample, the minimum sample size will be determined using Chin (1998)'s rule-of-thumb which establishes that a sample size should be at least 10 times (1) the largest number of formative indicators or (2) the largest number of independent variables impacting a dependent variable, whichever is greater. We do not have formative indicators in our research model, but the largest number of independent variables affecting a dependent variable (Internet use) is five. We plan to collect about 400 responses, which is adequate for the PLS estimation procedures that needs a minimum sample size of 50 respondents.

\section{Data Analysis (Future Step)}

Partial least squares (PLS) will be used to assess our research model, while SmartPLS will be used as an analysis tool (Ringle, Wende \& Becker, 2015). The reliability and convergent validity of our research model will be assessed through three tests: (1) item loadings should be equal to or higher than 0.7, (2) Cronbach's alpha and composite reliability values should be equal to or higher than 0.7 , and (3) average variance extracted (AVE) should be equal to or higher than 0.5 . As for discriminant validity, it will be checked by verifying that the square root of the AVEs is higher than the correlations among the constructs. 


\section{Issues in Information Systems}

Volume 20, Issue 4, pp. 188-197, 2019

In addition, multicollinearity issues will be assessed by examining variance inflation factor (VIF) values, which should be less than five (Hair, Ringle \& Sarstedt, 2011). Moreover, the absence of common method bias (CMB) will be guaranteed if no single factor accounts for the majority of the variance by performing the Harman's single-factor test.

\section{IMPLICATIONS (EXPECTED)}

In terms of theoretical implications, it is expected that this study may provide a framework that improves comprehension of the use of the Internet and its offline outcomes. The idea of offline outcomes would be better known and extended in the context of the three stages of the digital divide. This approach may allow us to highlight the importance of results derived from Internet use and how it can affect not only people's wellbeing but also society.

On a practical level, it would help to develop and manage new and better strategies to drive Internet users to reach positive outcomes (e.g., improve policymaker decisions). These results can be exhibited in either international conferences related to the field or in local forums where impact and use of ICT can be discussed. Also these conclusions can be helpful to interested groups that work with digital technologies.

\section{REFERENCES}

Ajzen, I. (2005). Attitudes, personality, and behavior. UK: McGraw-Hill Education.

Ajzen, I., \& Fishbein, M. (2005). The influence of attitudes on behavior. In D. Albarracín, B. T. Johnson, \& M. P. Zanna (Eds.), The handbook of attitudes (pp. 173-221). Mahwah, NJ: Lawrence Erlbaum Associates Publishers.

Bhatnagar, A., \& Ghose, S. (2004). Segmenting consumers based on the benefits and risks of Internet shopping. Journal of Business Research, 57(12), 1352-1360.

Bhattacherjee, A. (2001). Understanding information systems continuance: An expectation-confirmation model. MIS Quarterly, 25(3), 351-370.

Bhattacherjee, A., \& Premkumar, G. (2004). Understanding changes in belief and attitude toward information technology usage: A theoretical model and longitudinal test. MIS Quarterly, 28(2), 229-254.

Boase, J., Horrigan, J. B., Wellman, B., \& Rainie, L. (2006). The strength of internet ties: The internet and e-mail aid users in maintaining their social networks and provide pathways to help when people face big decisions. Washington, DC: The Pew Internet and American Life Project.

Bolton, R. N., \& Drew, J. H. (1991). A longitudinal analysis of the impact of service changes on customer attitudes. The Journal of Marketing, 55(1), 1-9.

Chang, Y., Shahzeidi, M., Kim, H., Park, M.-C. (2012). Gender digital divide and online participation: A crossnational analysis. Proceedings of the $19^{\text {th }}$ ITS Biennial Conference, Bangkok, Thailand.

Chang, Y., Wong, S. F., \& Park, M. C. (2016). A three-tier ICT access model for intention to participate online: A comparison of developed and developing countries. Information Development, 32(3), 226-242.

Chin, W. W. (1998). The partial least squares approach for structural equation modeling. In G. A. Marcoulides (Ed.), Modern methods for business research (pp. 295-336). Mahwah, NJ: Lawrence Erlbaum Associates.

D'Ambra, J., \& Wilson, C. S. (2004). Use of the World Wide Web for international travel: Integrating the construct of uncertainty in information seeking and the task-technology fit (TTF) model. Journal of the American Society for Information Science and Technology, 55(8), 731-742. 


\section{Issues in Information Systems}

Volume 20, Issue 4, pp. 188-197, 2019

DiMaggio, P., \& Bonikowski, B. (2008). Make money surfing the Web? The impact of Internet use on the earnings of U.S. workers. American Sociological Review, 73(2), 227-250.

DiMaggio, P., \& Hargittai, E. (2001). From the digital divide to digital inequality: Studying Internet use as penetration increases. NJ, USA: Center for Arts and Cultural Policy Studies, Woodrow Wilson School, Princeton.

Edwards, J. R., Cable, D. M., Williamson, I. O., Lambert, L. S., \& Shipp, A. J. (2006). The phenomenology of fit: Linking the person and environment to the subjective experience of person-environment fit. Journal of Applied Psychology, 91(4), 802-827.

Fink, C., \& Kenny, C. J. (2003). W(h)ither the digital divide?. info, 5(6), 15-24.

Fishbein, M. (2000). The role of theory in HIV prevention. AIDS care, 12(3), 273-278.

Fishbein, M., \& Ajzen, I. (2011). Predicting and changing behavior: The reasoned action approach. New York: Psychology Press.

Furneaux B. (2012) Task-Technology Fit Theory: A survey and synopsis of the literature. In: Dwivedi Y., Wade M., Schneberger S. (Eds.), Information Systems Theory (pp. 87-106). New York, NY: Springer.

Goodhue, D. L., \& Thompson, R. L. (1995). Task-technology fit and individual performance. MIS Quarterly, 19(2), 213-236.

Ha, Y. W., Kim, J., Libaque-Saenz, C. F., Chang, Y., \& Park, M.-C. (2015). Use and gratifications of mobile SNSs: Facebook and KakaoTalk in Korea. Telematics and Informatics, 32(3), 425-438.

Hair, J. F., Ringle, C. M., \& Sarstedt, M. (2011). PLS-SEM: Indeed a silver bullet. Journal of Marketing Theory and Practice, 19(2), 139-152.

Hargittai, E., \& Hinnant, A. (2008). Digital inequality: Differences in young adults' use of the internet. Communication Research, 35(5), 602-621.

Helsper, E. J. (2012). A corresponding fields model for the links between social and digital exclusion. Communication Theory, 22(4), 403-426.

Huang, J. L., Curran, P. G., Keeney, J., Poposki, E. M., \& DeShon, R. P. (2012). Detecting and deterring insufficient effort responding to surveys. Journal of Business and Psychology, 27(1), 99-114.

Kuhn, P., \& Mansour, H. (2014). Is Internet job search still effective? The Economic Journal, 124(581), 1213-1233.

Liao, C., Palvia, P., \& Chen, J. L. (2009). Information technology adoption behavior life cycle: Toward a Technology Continuance Theory (TCT). International Journal of Information Management, 29(4), 309-320.

Libaque-Saenz, C.F. (2016). Strategies for bridging the Internet digital divide in Peru: A benchmarking of South Korea and Chile. Proceedings of the 2016 International Conference on Information Resources Management (CONF-IRM) 2016, Cape Town, South Africa.

Lin,T. C., \& Huang, C. C. (2008). Understanding knowledge management system usage antecedents: An integration of social cognitive theory and task technology fit. Information \& Management, 45(6), 410-417.

Lu, H.-P., \& Yang, Y.-W. (2014). Toward an understanding of the behavioral intention to use a social networking site: An extension of task-technology fit to social-technology fit. Computers in Human Behavior, 34(May), 323-332. 
Marcolin, B. L., Compeau, D. R., Munro, M. C., \& Huff, S. L. (2000). Assessing user competence: Conceptualization and measurement. Information systems research, 11(1), 37-60.

Montaño, D. E., \& Kasprzyk, D. (2015). Theory of reasoned action, theory of planned behavior, and the integrated behavioral model. In K. Glanz, B. K. Rimer, \& K. "V." Viswanath (Eds.), Health behavior: Theory, research, and practice (pp. 95-124). San Francisco, CA, US: Jossey-Bass.

OECD. (2018). Bridging the rural digital divide. OECD Digital Economy Papers. February 2018 № 265.

OECD. (2001). Understanding the digital divide. Organisation for Economic Co-Operation and Development.

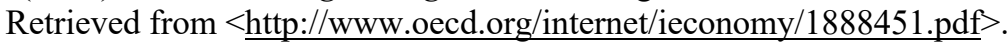

OECD. (n.d.). Bridging the digital divide. Organisation for Economic Co-Operation and Development. Retrieved from

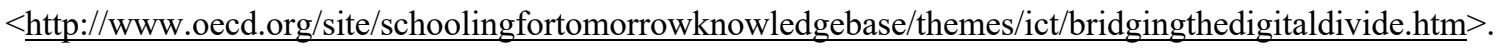

Oghuma, A. P., Chang, Y., Libaque-Saenz, C. F., Park, M.-C., \& Rho, J. J. (2015). Benefit-confirmation model for post-adoption behavior of mobile instant messaging applications: A comparative analysis of KakaoTalk and Joyn in Korea. Telecommunications Policy, 39(8), 658-677.

Oliver, R. L. (1981). Measurement and evaluation of satisfaction processes in retail settings. Journal of Retailing, 57(3), 25-48.

Petter, S., DeLone, W., \& McLean, E., (2008). Measuring information systems success: Models, dimensions, measures, and interrelationships. European Journal of Information Systems, 17(3), 236-263.

Ringle, C. M., Wende, S., \& Becker, J.-M. (2015). SmartPLS 3. Boenningstedt: SmartPLS GmbH, http://www. Smartpls. com

Sein, M., Bostrom, R. P., \& Olfman, L. (1999). Rethinking end-user training strategy: applying a hierarchical knowledge-level model. Journal of Organizational and End User Computing (JOEUC), 11(1), 32-39.

Somers, T.M., \& Nelson, K. (2001). The impact of critical success factors across the stages of enterprise resource planning implementations. Proceedings of the 34th Annual Hawaii International Conference on System Sciences (HICSS), Maui, USA.

Sousa, R. D. (2004). Complex information technology usage. Athens, US: University of Georgia.

Sousa, R., \& Goodhue, D. (2003). Understanding Exploratory Use of ERP Systems. Proceedings of the Americas Conference on Information Systems (AMCIS), Tampa, USA.

Steelman, Z. R., Hammer, B. I., \& Limayem, M. (2014). Data collection in the digital age: Innovative alternatives to student samples. MIS Quarterly, 38(2), 355-378.

Sylvester, D. E., \& McGlynn, A. J. (2010). The digital divide, political participation, and place. Social Science Computer Review, 28(1), 64-74.

UNDP. (2001). Human development report 2001: Making new technologies work for human development. New York, USA: United Nations Development Programme.

van Deursen, A. J. A. M., \& van Dijk, J. A. G. M. (2011). Internet skills and the digital divide. New Media \& Society, 13(6), 893-911. 


\section{Issues in Information Systems}

Volume 20, Issue 4, pp. 188-197, 2019

van Deursen, A. J. A. M., van Dijk, J. A. G. M. \& Peters, O. (2012). Proposing a survey instrument for measuring operational, formal, information, and strategic internet skills. International Journal of Human-Computer Interaction, 28(12), 827-837.

van Deursen, A. J. A. M., Helsper, E. J., \& Eynon, R. (2016). Development and validation of the Internet Skills Scale (ISS). Information, Communication \& Society, 19(6), 804-823.

van Deursen, A. J. A. M., \& Helsper, E. J. (2015). The third level digital divide: Who benefits most from being online? In L. Robinson, S. R. Cotten, \& J. Schulz (Eds.), Communication and Information Technologies Annual (pp. 29-52). UK: Emerald Group Publishing Limited.

van Deursen, A. J. A. M., van Dijk, J. A. G. M., \& ten Klooster, P. M. (2015). Increasing inequalities in what we do online: A longitudinal cross sectional analysis of Internet activities among the Dutch population (2010 to 2013) over gender, age, education, and income. Telematics and Informatics, 32(2), 259-272.

van Dijk, J. A. G. M. (2006). Digital divide research, achievements and shortcomings. Poetics, 34(4-5), 221-235.

van Laar, E., van Deursen, A. J. A. M., van Dijk, J. A. G. M., \& de Haan, J. (2017). The relation between 21stcentury skills and digital skills: A systematic literature review. Computers in Human Behavior, 72, 577-588. 